\title{
Pharmacological Management of Obese Patients with Type 2 Diabetes amid COVID-19 Pandemic
}

\author{
Chia Siang Kow ${ }^{1}$ (D) Syed Shahzad Hasan ${ }^{2}$ \\ Published online: 25 June 2020 \\ (C) Springer Science+Business Media, LLC, part of Springer Nature 2020
}

The hypothesis put forward by Iannelli et al. [1] to suggest that obesity is the missing piece accounting for the variation in the severity of coronavirus disease 2019 (COVID-19) in their discussion entitled "Obesity and COVID-19: ACE 2, the Missing Tile" has been of our great interest. The authors described the association of obesity with an imbalance in the renalangiotensin-aldosterone system, where angiotensin-converting enzyme 2, the entry receptor of severe acute respiratory syndrome coronavirus 2 , is largely expressed in adipose tissue. Therefore, obese individuals may develop a more overwhelming inflammatory response compared with non-obese individuals upon acquisition of COVID-19. The hypothesis has somewhat been confirmed in the recent CORONADO study [2], a nationwide multicenter observational study among diabetic patients hospitalized for COVID-19 in 53 French centers which reported body mass index (BMI) as the only independent preadmission predictor associated with the primary outcome of combined tracheal intubation for mechanical ventilation and/or death within 7 days of admission in a multivariable analysis that included characteristics before admission (adjusted odds ratio $=$ 1.28 ; $95 \%$ confidence interval 1.10-1.47). In fact, in an earlier retrospective study [3] to determine the clinical outcomes of diabetic patients with COVID-19 in association with glucoselowering medications, it was reported that long-term insulin usage, which may lead to weight gain, was associated with progression to severe or critical illness or in-hospital death (adjusted odds ratio $=3.58 ; 95 \%$ confidence interval $1.37-9.35$ ).

Since diabetes is one of the leading risk factors for COVID19 [4], we feel that glucose-lowering medications with weight

Chia Siang Kow

chiasiang_93@hotmail.com

1 School of Postgraduate Studies, International Medical University, Kuala Lumpur, Malaysia

2 School of Applied Sciences, University of Huddersfield, Huddersfield, UK loss effect such as glucagon-like peptide 1 (GLP-1) receptor agonists should be allowed to play a greater role in the pharmacological treatment of type 2 diabetes amid COVID-19 pandemic, especially among patients with type 2 diabetes who are currently overweight or obese. Weight loss is common with GLP-1 receptor agonists, which may be partly attributable to the effects of GLP-1 on slowed gastric emptying and their well-recognized side effects of nausea and vomiting. In a Cochrane systematic review [5] of 17 randomized trials comparing GLP-1 receptor agonists with placebo or an active comparator (insulin glargine, dipeptidyl peptidase-4 inhibitor, thiazolidinedione, sulfonylurea) in patients with type 2 diabetes and being suboptimally controlled on one or two oral agents (metformin and/or a sulfonylurea), patients randomly assigned to GLP-1 receptor agonists had a weight reduction of approximately 1.5 to $2.5 \mathrm{~kg}$ over 30 weeks. In addition, weight loss has also been reported in patients without diabetes who received GLP-1 receptor agonists. In a 56-week, double-blind trial comparing liraglutide ( $3 \mathrm{mg}$ once daily) with placebo injection in 3731 patients who had a BMI of $\geq 30 \mathrm{~kg} / \mathrm{m}^{2}$ or $\geq 27 \mathrm{~kg} / \mathrm{m}^{2}$ with dyslipidemia and $/$ or hypertension, mean weight loss was significantly greater in the liraglutide group compared with placebo $(-8.4 \mathrm{~kg}$ versus $2.8 \mathrm{~kg}$ ) [6]. Indeed, liraglutide has been approved for chronic weight management (as an adjunct to diet and exercise) in obese patients or overweight patients with at least one weightassociated comorbidity. Other glucose-lowering medications associated with weight loss include sodium-glucose co-transporter 2 (SGLT2) inhibitors. SGLT2 inhibitors directly cause body weight loss via glucose excretion (calorie loss) in the kidneys. In a meta-analysis [7] of long-term trials (one to 2 years) comparing SGLT2 inhibitors with placebo, there was a significant reduction in weight with SGLT2 inhibitors (mean difference at 2 years $-2.99 \mathrm{~kg}$; $95 \%$ confidence interval -3.64 to -2.34 ).

Considering that obesity may be the main driving factor of worse prognosis among COVID-19 patients with diabetes, the diabetes treatment goal in priority amid COVID-19 pandemic, even among non-overweight/obese patients with type 2 diabetes, should be to minimize weight gain, while the diabetes 
treatment goal in priority amid COVID-19 pandemic among patients with type 2 diabetes who are overweight/obese should be to achieve weight loss. Hence, GLP-1 receptor agonists and SGLT2 inhibitors can be used to substitute/as an adjunct to other potential weight gaining glucose-lowering medications such as insulin, sulfonylureas, and thiazolidinediones. In fact, it appears that potent GLP-1 receptor agonists are at least as effective as basal insulin. To illustrate, in a 26-week randomized controlled trial [8] that included type 2 diabetic patients with hemoglobin $\mathrm{A} 1 \mathrm{C}$ as high as $11 \%$ (mean $\mathrm{A} 1 \mathrm{C}$ $8.3 \%$ ), the reduction in hemoglobin A1C was greater with liraglutide $(-1.33$ versus -1.09 percentage points with glargine), with weight loss of $1.8 \mathrm{~kg}$ in the liraglutide arm and weight gain of $1.6 \mathrm{~kg}$ in the glargine arm. Specifically, SGLT2 inhibitors which are not as potent as other glucose-lowering medications that could cause weight gain can be used as an adjunct to the patients' current antidiabetic regimen to minimize weight gain. Nevertheless, we recognize that the relatively high cost of GLP-1 receptor agonists and SGLT2 inhibitors might limit their access to all patients with type 2 diabetes and therefore major emphasis could also be placed on diet and lifestyle modification to prevent weight gain or to promote weight loss. Clinicians managing patients with type 2 diabetes amid COVID-19 pandemic should discard the concept that weight gain from glucoselowering medications is not important though microvascular complications are reduced despite weight gain, but instead should place minimization of weight gain/promotion of weight loss as one of the primary goals of treatment of type 2 diabetes amid COVID-19 crisis.

\section{Compliance with Ethical Standards}

Conflict of Interest The authors declare that they have no conflict of interest.
Ethical Approval This article does not contain any studies with human participants or animals performed by any of the authors.

Informed Consent Informed consent does not apply.

\section{References}

1. Iannelli A, Favre G, Frey S, et al. Obesity and COVID-19: ACE 2, the missing tile. Obes Surg. 2020;2020:1-3.

2. Cariou B, Hadjadj S, Wargny M, et al. Phenotypic characteristics and prognosis of inpatients with COVID-19 and diabetes: the CORONADO study. Diabetologia. 2020;2020:1-16.

3. Chen Y, Yang D, Cheng B, et al. Clinical characteristics and outcomes of patients with diabetes and COVID-19 in association with glucose-lowering medication. Diabetes Care. 2020;2020:dc200660.

4. Marhl M, Grubelnik V, Magdič M, et al. Diabetes and metabolic syndrome as risk factors for COVID-19. Diabetes Metab Syndr. 2020;14(4):671-7.

5. Shyangdan DS, Royle P, Clar C, et al. Glucagon-like peptide analogues for type 2 diabetes mellitus. Cochrane Database Syst Rev. 2011;2011(10):CD006423.

6. Pi-Sunyer X, Astrup A, Fujioka K, et al. A randomized, controlled trial of $3.0 \mathrm{mg}$ of liraglutide in weight management. N Engl J Med. 2015;373(1):11-22.

7. Liu XY, Zhang N, Chen R, et al. Efficacy and safety of sodiumglucose cotransporter 2 inhibitors in type 2 diabetes: a metaanalysis of randomized controlled trials for 1 to 2 years. J Diabetes Complicat. 2015;29(8):1295-303.

8. Russell-Jones D, Vaag A, Schmitz O, et al. Liraglutide vs insulin glargine and placebo in combination with metformin and sulfonylurea therapy in type 2 diabetes mellitus (LEAD-5 met+SU): a randomised controlled trial. Diabetologia. 2009;52(10):2046-55.

Publisher's Note Springer Nature remains neutral with regard to jurisdictional claims in published maps and institutional affiliations. 